\title{
АКАДЕМИЧЕСКИЙ БУНИН
}

DOI 10.22455/2541-8297-2020-16-68-79

УДК 821.161 .1

\section{Проза И.А. Бунина. Выбор основного текста (к постановке вопроса)"}

(C) 2020, Т.М. Двинятина, С.Н. Морозов

\begin{abstract}
Аннотация: Статья посвящена проблеме основного текста прозы И.А. Бунина, который должен быть положен в основу научного Полного собрания сочинений писателя. Этот вопрос наиболее проработан по отношению к поэзии Бунина, изучение текстологии прозы писателя только начинается. Многоступенчатая работа Бунина со своими произведениями, которая велась до и после их выхода в свет, заставляет вырабатывать такие способы подачи текста, которые учитывали бы и собственную работу автора с ним, и отражение произведения в истории литературы и сознании современных ему читателей и критиков. В статье, представляющей собой первый общий очерк на данную тему, обсуждаются различные варианты решения этой проблемы. Рассмотрены четыре группы прозаических произведений писателя (ранние, дореволюционные, эмигрантские, не напечатанные автором), и изложены методы выбора основного текста по отношению к каждой группе. Обосновывается структура томов будущего научного собрания сочинений писателя. Выявлены проблемные вопросы датировок рассказов Бунина в связи с их хронологическим местом в будущем научном издании и относительно выбора основного текста данных произведений. В результате изложены основные принципиальные методы выбора основного текста прозы в научном Полном собрании сочинений И.А. Бунина. В статье подчеркивается, что выполнить последнюю творческую волю автора в связи с незавершенностью его работы со своим наследием (отбор произведений для будущих изданий, несогласованная правка) невозможно.

Ключевые слова: И.А. Бунин, архивные материалы, текстология, выбор основного текста, собрание сочинений

Информация об авторах: Татьяна Михайловна Двинятина, д.ф.н., ведущий научный сотрудник, Институт русской литературы (Пушкинский Дом) Российской академии наук, Санкт-Петербург, Россия; старший научный сотрудник, Институт мировой литературы им. А.М. Горького Российской академии наук, Москва, Россия. E-mail: tatiana.dvinyatina@gmail.com
\end{abstract}

* Исследование выполнено в Институте мировой литературы им. А.М. Горького РАН при финансовой поддержке Российского научного фонда (проект № 17-18-01410-П «Академический Бунин. Источниковедение, текстология, методология»). 
Сергей Николаевич Морозов, к.ф.н., старший научный сотрудник, Институт мировой литературы им. А.М. Горького Российской академии наук, Москва, Россия. E-mail: morozov.sn@yandex.ru

Цитирование: Двинятина Т.М., Морозов С.Н. Проза И.А. Бунина. Выбор основного текста (к постановке вопроса) // Литературный факт. 2020. № 2 (16). C. 68-79. DOI 10.22455/2541-8297-2020-16-68-79

Одним из самых существенных, если не главным, вопросом предподготовки Полного научного собрания сочинений И.А. Бунина является вопрос о выборе основного текста его произведений. Случай Бунина особый в истории текстологии. Бунин всю свою долгую творческую жизнь очень внимательно относился к своим произведениям, правил их перед каждой новой публикацией, до конца жизни продолжал вносить правку в рабочие экземпляры своих книг и собрания сочинений (главным образом, в тома собрания сочинений 1934-1936 гг. издательства «Петрополис» и «нивское» собрание сочинений 1915 г. $\left.{ }^{1}\right)$.

Как показала работа с поэтическим наследием Бунина ${ }^{2}$, правка автором своих текстов шла не только до, но и после выхода в свет его важнейших изданий, она велась в разные годы, но сразу в нескольких экземплярах одних и тех же томов и не была сведена к единому варианту для всех текстов. В результате как минимум каждое восьмое стихотворение, включенное в основной корпус, не имеет итоговой версии, и уже одно это делает невозможным воплощение в научном издании принципа последней авторской воли. Поэтому относительно стихотворений Бунина было принято решение о выборе в качестве основного текста последней / главной прижизненной публикации (прежде всего названных выше собраний сочинений и далее по другим изданиям). От этого правила были сделаны единичные и строго определенные отступления, но, за исключением нескольких текстов, генеральный принцип выбора текста оказалось возможным провести через всё издание и, значит, через всю лирику Бунина.

\footnotetext{
1 Бунин И.А. Собрание сочинений: В 11 т. Берлин: Петрополис, 1934-1936; Бунин И.А. Полное собрание сочинений: В 6 т. Пг.: Изд-во т-ва А.Ф. Маркс, 1915. (Прилож. к ж. «Нива»).

${ }_{2}$ Бунин И.А. Стихотворения: В 2 т. / Вступ. ст., сост., подгот. текста и примеч. Т.М. Двинятиной. СПб., 2014. (Новая Библиотека поэта).
} 
Относительно прозы Бунина - самого значительного сегмента его творческого наследия - вопрос об основном тексте приходится решать заново. В последнее время появилось несколько значительных работ по текстологии конкретных произведений ${ }^{3}$. В настоящей статье предпринята попытка рассмотреть вопрос выбора основного текста в прозе Бунина в целом. Какой бы долгой, пестрой и запутанной ни была история работы автора со своими произведениями, сколько бы текстологических задач он ни оставил своим издателям, в выработке основ научного издания стоит стремиться к максимально ясному и внутренне непротиворечивому представлению его наследия, к определению тех принципов подачи текстов, которые были бы применимы если не ко всем произведениям, то, во всяком случае, к хронологически и жанрово близким группам произведений, отвечали бы тем установкам, которые автор принимал в момент создания произведений и работы над ними, и не входили бы в конфликт с тем текстом, который стал явлением в истории культуры и литературной критики.

Применительно к Бунину перед издателями стоит прежде всего два вопроса: какой текст считать основным и как учитывать позднюю правку автора, имея в виду ее градации от замены отдельных слов до существенных сокращений и изменений композиции произведения. Вслед за ними отдельным, важнейшим вопросом встает вопрос о датировках тех произведений, к которым автор по несколько раз возвращался в разные годы, и, следовательно, о расположении и порядке текстов в издании.

3 Морозов С.Н. «Окаянные дни» И.А. Бунина: к истории текста // Текстологический временник: Вопросы текстологии и источниковедения. М., 2012. Кн. 2. С. 302-311; Морозов С.Н. Проблема датировки прозы И.А. Бунина // Литературный факт. 2017. № 4. С. 317-325; Пономарев E.P. От «Жизни Арсеньева» к «Темным аллеям»: Эмигрантское творчество И.А. Бунина в свете последних текстологических изысканий // Русская литература. 2017. № 4. С. 228-238; Морозов С.Н. Рассказ И.А. Бунина «Роза Иерихона». История текста // Зборник Матице Српске за славистику. Белград, 2018. Т. 94. С. 153-158; Бунин И.А. Рассказы круга «Темных аллей»; <Смерть в Ялте>; Отдельные наброски; <Путешествия на Цейлон>; Наброски, тематически близкие роману «Жизнь Арсеньева»; Наброски, тематически близкие книге «Темные аллеи»; Наброски, тематически близкие книге «Воспоминания» / Подгот. текста, предисл. и примеч. Е.Р. Пономарева // И.А. Бунин. Новые исследования и материалы: В 4 кн. Кн. 1 / Ред.-сост. О.А. Коростелев, С.Н. Морозов. М., 2019. С. 79-322. (Литературное наследство. Т. 110); Морозов С.Н. Текстология рассказа И.А. Бунина «Антоновские яблоки» // Творчество И.А. Бунина в историко-литературном контексте (биография, источниковедение, текстология) / Ред.-сост. О.А. Коростелев, С.Н. Морозов. М., 2019. С. 704-727. (Академический Бунин; вып. 1) и др. 
Этот вопрос, в свою очередь, выводит нас на проблему общей структуры Полного собрания сочинений.

В свете обозначенных задач всё прозаическое наследие Бунина можно условно поделить на четыре группы: 1) ранние произведения, которые были опубликованы только один-два раза или вообще не публиковались автором; 2) доэмигрантские произведения, которые Бунин неоднократно публиковал в России, а большую их часть значительно исправлял и вновь публиковал в эмиграции; 3) эмигрантские произведения, публиковавшиеся автором несколько раз с соответствующей правкой; 4) эмигрантские произведения, которые остались неопубликованными при жизни Бунина.

Первая группа нам представляется наименее противоречивой, т.к. ранние прозаические произведения имеют один текст: автограф для неопубликованных произведений или одну (иногда 2-3) публикацию текста, который не имеет автографа. Таковы 23 рассказа, написанные в 1887-1902 гг.

Вторая группа произведений является наиболее спорной и сложной, т.к. в нее входят доэмигрантские рассказы и повести, которые Бунин неоднократно печатал в России, а большую их часть публиковал и в эмиграции. Именно для этой группы необходимо четкое и обоснованное решение по выбору основного текста и публикации других вариантов и редакций. В нее входит 95 произведений 1892-1919 гг, из которых 80 произведений 1894-919 гг. Бунин печатал в эмиграции после внесения значительной правки. Следует подчеркнуть, что если произведения 1894-1906 гг. публиковались писателем в эмиграции выборочно, то произведения 1907-1919 гг. были напечатаны в эмиграции все без исключения.

Главная проблема с произведениями второй группы состоит в том, что для них следует выработать свой принцип отбора основного текста. Он должен учитывать, в частности, актуальный литературный и общественный контекст, в котором эти произведения выходили в свет: многие из них становились явлениями, обращающими на себя особое внимание критики и читателей. Это относится, например, к центральному произведению дореволюционного творчества Бунина - повести «Деревня», которая была закончена и опубликована в 1910 г. До революции повесть печаталась четыре раза, в эмиграции - два раза. Произведение стало событием не только в творчестве Бунина, но и в русской литературе и общественной жизни в целом. В эми- 
грации Бунин значительно сократил и во многом переработал «Деревню». Таким образом, мы имеем две редакции повести: дореволюционную и эмигрантскую. Возникает вопрос: какой текст выбрать в качестве основного? Если следовать принципу последней авторской воли, то в качестве основного надо выбирать текст Собрания сочинений (т. 2. Берлин, 1934). Если учитывать общественное и культурное значение произведения в той исторической ситуации, в которой оно вышло в свет, то в качестве основного текста надо выбрать редакцию Полного собрания сочинений (1915). В первом случае дореволюционная редакция должна быть полностью напечатана в разделе «Другие редакции и варианты», а во втором случае в этот раздел попадает редакция эмигрантская, более поздняя.

Та же ситуация с повестью «Суходол» (1911): она три раза была напечатана в России, два раза - в эмиграции, и в эмигрантской редакции текст претерпел значительные изменения.

Можно сказать, что это относится почти ко всем произведениям второй группы, которые печатались позднее за границей. При переиздании их в эмиграции Бунин прежде всего значительно сокращал текст, частично перерабатывал его, и в результате получалась новая редакция. Это наглядно видно и на примере раннего рассказа «Антоновские яблоки» $(1900)^{4}$.

Нам представляется, что в отношении этой группы текстов следует принять неординарное решение (конечно, при условии возможных исключений): для рассказов и повестей 1894-1919 гг, переиздававшихся автором в эмиграции, в качестве основного текста выбирается последняя авторская публикация в данных хронологических рамках (в большинстве случаев это текст «нивского» собрания сочинений 1915 г.), а более поздние эмигрантские варианты и редакции этих произведений публикуются в соответствующем разделе приложения. Такое решение позволит поместить в качестве основного текста то произведение, которое было написано в конкретный исторический период. В эмиграции автор придавал этим рассказам и повестям несколько другие черты и характеристики, изменял композицию и настроение произведений, что отражалось и на их содержании, и на восприятии творчества Бунина современным читателем.

\footnotetext{
${ }^{4}$ Подробнее см.: Морозов С.Н. Текстология рассказа И.А. Бунина «Антоновские яблоки».
} 
Третья группа, охватывающая только эмигрантские прозаические произведения Бунина, заключает в себе отдельную проблему: при выборе основного текста конкретного рассказа встает вопрос о его месте в хронологическом ряду. Это хорошо видно на примере рассказа «Бернар», первая редакция которого была создана в 1927 г. Рассказ публиковался при жизни писателя пять раз, на каждом этапе Бунин вносил в текст небольшие исправления, но главные изменения касались финала. Авторская рефлексия, проецирующая образ героя на собственную жизнь, появилась только в публикации 1929 г. (Последние новости [Париж]. 1929, 17 марта): «Ах, если бы заслужить и себе право сказать в некий час то, что с такой радостной гордостью сказал, умирая, Бернар!». В первой публикации рассказа (Сегодня [Рига]. 1927, 12 июня) этой концовки нет. В сборнике «Божье древо» (Париж, 1931) концовка изменена: «Каждый, каждый из нас должен заслужить себе право сказать в некий час то, что с такой радостной гордостью сказал, умирая, Бернар». В Собрании сочинений (Т. 9. Берлин, 1935) концовка сокращена: «Каждый, каждый из нас должен заслужить себе право сказать в некий час так, как сказал, умирая, Бернар». В последней прижизненной публикации рассказа в сборнике «Весной в Иудее. Роза Иерихона» (Нью-Йорк, 1953) концовка полностью изменена: «Мне кажется, что я, как художник, заслужил право сказать о себе, в свои последние дни, нечто подобное тому, что сказал, умирая, Бернар» (авторская дата под текстом: 1952 г.).

Таким образом, в хронологическом ряду рассказ «Бернар» должен стоять среди произведений 1927 г., но в редакции 1952 г. его никак нельзя поставить на это место из-за вышеприведенной концовки. Во всех современных изданиях произведений Бунина этот рассказ всегда замыкает раздел художественной прозы и имеет одну дату: 1952 г. Как видим, эта датировка некорректна. Рассказ «Бернар» должен размещаться по дате написания (1927) с широкой датировкой: 1927-1952. Но тогда возникает вопрос: в какой редакции - 1929, 1931 или 1935 г.? Думается, что для данного рассказа необходимо в качестве исключения принять индивидуальное решение: в основной текст поместить редакцию 1935 г. из Собрания сочинений, а в разделе вариантов привести концовку 1952 г.

Для текстов наподобие рассказа «Цикады» (1925), имеющих несколько редакций (черновую, журнальную и книжную), можно применить классическую методику: основной текст - 
последняя редакция Собрания сочинений (Т. 9. Берлин, 1935), черновая редакция полностью публикуется в разделе редакций, a разночтения между журнальной и книжными редакциями приводятся в разделе вариантов.

Проблему выбора основного текста придется решать и для такого сложного в этом отношении произведения, как «Окаянные дни». У художественного дневника Бунина две редакции: газетная (печаталась в газете «Возрождение» в 1925-1927 гг.) и книжная (Собрание сочинений. Т. 10. Берлин, 1935). Для Собрания сочинений Бунин отредактировал произведение, местами смягчил оценки и критические пассажи и, конечно, сократил текст. В этом случае можно поступить по-разному, в зависимости от принятого правила выбора основного текста для всей прозы писателя. Скорее всего, и к этому произведению будет применена классическая методика — в качестве основного текста будет избрана книжная редакция.

Четвертая группа - неопубликованные при жизни Бунина произведения - особых сложностей не вызывает. Источником основного текста в таких случаях является наиболее репрезентативный автограф, при необходимости дополняемый в приложении разночтениями, зафиксированными в других архивных материалах.

В целом, как мы увидели, проблема выбора основного текста для прозы Бунина стоит довольно остро. Решение ее должно быть в нескольких плоскостях. Думается, в целом для будущего научного Полного собрания сочинений Бунина можно принять следующее общее текстологическое положение: в качестве основного текста выбирается последняя авторская публикация прозаических произведений, неопубликованные автором ранние и поздние произведения печатаются по сохранившимся автографам. Из этого правила делается исключение для текстов, написанных в 1894-1919 гг. и переиздававшихся автором в эмиграции: основной текст для этих рассказов и повестей дается по последней доэмигрантской авторской публикации, а разночтения с более поздними эмигрантскими редакциями приводятся в соответствующем разделе.

В структуре издания этот принцип может быть выражен более дробной организацией раздела «Другие редакции и варианты». Для текстов второй и, видимо, отчасти третьей группы в этот раздел, помимо ранних версий текста (что обычно подразумевается в этой части собрания), отдельной рубрикой 
следует включить поздние «постредакции» уже прозвучавших в литературе и впоследствии переработанных или просто исправленных автором произведений. Они, в свою очередь, будут члениться на те, которые были напечатаны при жизни Бунина, и те, которые остались только в его рабочих экземплярах томов (в случае, если авторская правка привела к созданию новой редакции произведения). Выделять ли эту рубрику в отдельный раздел в составе приложений или печатать «постредакции» в одном хронологическом ряду с более ранними, предшествующими основной редакции версиями текста, - на этот вопрос можно будет ответить после фронтальной сверки всех редакций всех прозаических произведений Бунина.

Наконец, еще один существенный вопрос, связанный с выбором основного текста: включать ли в основной текст позднейшую правку Бунина из его рабочих экземпляров книг и томов Собрания сочинений 1934-1936 гг. (Петрополис). В данном случае речь идет о той правке, которая касалась отдельных фрагментов текста и не приводила к созданию новой редакции. Но как при позднейшем обращении Бунина к своим прежним стихам, так и при его неоднократной корректировке своих прозаических произведений эта правка часто оставалась несогласованной, не сведенной воедино по разным рабочим экземплярам одних и тех же томов. И даже если бы эта правка была проведена Буниным согласованно, включение ее в основной текст произведения привело бы к созданию такого варианта текста, который на определенном (позднем) этапе был только фактом самосознания автора, но так и не стал фактом истории литературы. Исходя из этого, мы полагаем, что всю подобную правку Бунина следует приводить именно в разделе вариантов.

Проблема выбора основного текста и оставленные Буниным указания насчет его будущих изданий тесно связаны с общей структурой Полного собрания сочинений и композицией отдельных его томов. Как известно, в своих литературных завещаниях Бунин просил не печатать его ранние произведения, а ввести в будущее Собрание сочинений только те произведения, которые включены в Собрание сочинений (Петрополис), книгу «Темные аллеи», отдельно перечисленные им сочинения и переводы. В Полном собрании сочинений осуществить это пожелание невозможно, в него по определению входят все известные произведения писателя. 
В самой структуре и композиции томов можно было бы дать представление о том, каким именно составом текстов Бунин хотел войти в историю литературы и каково было его отношение к своим произведениям, когда он задумывался о своем наследии в целом. В таком случае том будущего собрания сочинений мог бы состоять из двух разделов: 1) сочинения, включенные Буниным в будущее Собрание сочинений, 2) сочинения, не вошедшие в Собрание сочинений. Но даже при таком подходе точного соблюдения воли автора в рамках первого раздела достичь не удастся: в конце жизни, отбирая произведения для посмертного издания, Бунин не закончил работу по определению его состава. В рабочих экземплярах томов Собрания сочинений (Петрополис), Полного собрания сочинений (Пг., 1915), отдельных сборников не только правка, но и отбор текстов разнятся; относительно некоторых произведений Бунин колебался — включал то или иное произведение, затем мог отменить свое решение и вновь к нему вернуться.

Следует напомнить, что в Собрание сочинений (Петрополис) Бунин включил прозу только 1907-1933 гг. Лишь в «литературном завещании» 1951 г. он обратил внимание на более раннюю прозу и ввел в будущее собрание сочинений отдельные рассказы 1894-1909 гг., точно указав их заглавия. Однако относительно поздних рассказов, оставшихся неопубликованными, такой точности в завещании нет. При этом он добавил: «Всё — и стихи и проза, — что я не ввожу в это собрание моих сочинений, напечатать, если это нужно, как приложение К нему $\rangle^{5}$.

Здесь может быть два варианта решения вопроса: для поэзии (т.к. в ней нет согласованного отбора) давать в первом разделе все стихотворения, печатавшиеся Буниным в его сборниках и собраниях сочинений, а для прозы - отобранные автором произведения по завещанию. Однако это решение внесет некоторый разнобой в структуру будущего научного собрания сочинений писателя, которая должна подчиняться единым принципам. Поэтому в Полном собрании сочинений Бунина, на наш взгляд, надо принять за основу следующее деление основных текстов произведений писателя: 1) произведения, вошедшие в авторские издания, 2) произведения, не вошедшие в авторские издания (за ними могут следовать раз-

${ }^{5}$ Бунин И.А. Собрание сочинений: В 9 т. / Под общ. ред. А.С. Мясникова, Б.С. Рюрикова, А.Т. Твардовского. Т. 9. М., 1967. С. 483. 
делы неопубликованных, неоконченных произведений и т.д.). Надо отметить, что относительно прозы это деление коснется только рассказов 1887-1903 гг. Все остальные рассказы и повести включались Буниным в авторские издания, за исключением отдельных 17 рассказов 1925-1944 гг., появившихся только в периодике. Оставшиеся в архиве Бунина 16 рассказов 1943-1946 гг., не публиковавшиеся при жизни писателя, также войдут во второй раздел соответствующего тома.

Вырабатывая принципы научного собрания сочинений Бунина, следует подчеркнуть, что невозможность выполнить волю автора обусловлена прежде всего нечеткостью ее выражения, незавершенностью работы писателя со своим наследием. Это обстоятельство резонирует с историческим принципом, согласно которому произведения того или иного автора появлялись и прочитывались в конкретном историческом и литературном контексте, получали те или иные отклики современников, становились фактами литературного процесса определенного времени. Научное собрание сочинений призвано представить не только и не столько ту картину, которую автор хотел составить в конце своей жизни, но прежде всего ту, которая создавалась им на протяжении всей его творческой биографии и которой он объективно остался в истории литературы.

Настоящая статья призвана поставить сложные, неоднозначные вопросы бунинской текстологии прозы и предложить возможные пути их решения в целом. Безусловно, при непосредственном начале работы над подготовкой Полного собрания сочинений Бунина будут возникать другие, более частные проблемы, требующие индивидуального подхода к их решению. Но неизбежные будущие уточнения (и, возможно, исключения из очерченных здесь правил) не могут заслонить ясно сознаваемой необходимости: принципы будущего научного издания должны учитывать всё многообразие работы Бунина со своими текстами, быть точными, последовательными и едиными для всего собрания.

\section{Литература}

Бунин И.А. Стихотворения: В 2 т. / Вступ. ст., сост., подгот. текста и примеч. T.М. Двинятиной. СПб.: Изд-во Пушкинского Дома; Вита Нова, 2014. (Новая Библиотека поэта). 
Бунин И.А. Рассказы круга «Темных аллей»; <Смерть в Ялте>; Отдельные наброски; <Путешествия на Цейлон>; Наброски, тематически близкие роману «Жизнь Арсеньева»; Наброски, тематически близкие книге «Темные аллеи»; Наброски, тематически близкие книге «Воспоминания» / Подгот. текста, предисл. и примеч. Е.Р. Пономарева // Литературное наследство. Т. 110: И.А. Бунин. Новые исследования и материалы. В 4 кн. Кн. 1 / Ред.-сост. О.А. Коростелев, С.Н. Морозов. М.: ИМЛИ РАН, 2019. С. 79-322.

Морозов С.Н. «Окаянные дни» И.А. Бунина: к истории текста // Текстологический временник. Вопросы текстологии и источниковедения. Кн. 2. М.: ИМЛИ РАН, 2012. C. 302-311.

Морозов С.Н. Проблема датировки прозы И.А. Бунина // Литературный факт. 2017. № 4. C. 317-325.

Морозов С.Н. Рассказ И.А. Бунина «Роза Иерихона». История текста // Зборник Матице Српске за славистику. Т. 94. Белград: Нови Сад, 2018. С. 153-158.

Морозов С.Н. Текстология рассказа И.А. Бунина «Антоновские яблоки» // Творчество И.А. Бунина в историко-литературном контексте (биография, источниковедение, текстология) / Ред.-сост. О.А. Коростелев, С.Н. Морозов. М.: Литфакт, 2019. С. 704-727. (Академический Бунин. Вып. 1).

Пономарев E.P. От «Жизни Арсеньева» к «Темным аллеям»: Эмигрантское творчество И.А. Бунина в свете последних текстологических изысканий // Русская литература. 2017. № 4. С. 228-238.

\section{References}

Bunin I.A. Stikhotvoreniia [Poems], in 2 vols., intro., comp., ed., comment. T.M. Dvinyatina, series: Novaia Biblioteka poeta. St. Petersburg, Pushkin House Publ., Vita Nova Publ., 2014. (In Russ.)

Bunin I.A. Rasskazy kruga "Temnykh allei”; <Smert' v Ialte>; Otdel'nye nabroski; <Puteshestviia na Tseilon>; Nabroski, tematicheski blizkie romanu 'Zhizn' Arsen'eva"; Nabroski, tematicheski blizkie knige "Temnye allei"; Nabroski, tematicheski blizkie knige "Vospominaniia" [Stories of the "Dark alleys" circle; $<$ Death in Yalta $>$; Individual sketches; $<$ Travels to Ceylon>; Sketches thematically close to the novel "Life of Arsenyev"; Sketches thematically close to the book "Dark alleys"; Sketches thematically close to the book "Memoirs"], ed., intro., comment. E.R. Ponomarev. Literaturnoe nasledstvo. T. 110: I.A. Bunin. Novye issledovaniia i materialy [Literary heritage. Vol. 110: I.A. Bunin. New studies and materials], in 4 books, book 1, ed. O.A. Korostelev, S.N. Morozov. Moscow, Institute of World Literature Publ., 2019, pp. 79-322. (In Russ.).

Morozov S.N. "Okaiannye dni" I.A. Bunina: k istorii teksta ["Damned days" by I.A. Bunin: on the text history]. Tekstologicheskii vremennik. Voprosy tekstologii $i$ istochnikovedeniia [Textology chronicle. Text criticism and source study issues], book 2 . Moscow, Institute of World Literature Publ., 2012, pp. 302-311. (In Russ.)

Morozov S.N. Problema datirovki prozy I.A. Bunina [The issue of dating I.A. Bunin's prose]. Literaturnyi fakt, 2017, no. 4, pp. 317-325. (In Russ.)

Morozov S.N. Rasskaz I.A. Bunina "Roza Ierikhona". Istoriia teksta [I.A. Bunin's short story "The Rose of Jericho". Text history]. Zbornik Matitse Srpske za slavistiku, vol. 94. Belgrad, Novi Sad Publ., 2018, pp. 153-158. (In Russ.)

Morozov S.N. Tekstologiia rasskaza I.A. Bunina "Antonovskie iabloki" [Text criticism of I.A. Bunin's short story "Antonovka apples"]. Tvorchestvo I.A. Bunina v istoriko-literaturnom kontekste (biografiia, istochnikovedenie, tekstologiia) [I.A. Bunin's 
works in historical and literary context (biography, source study, text criticism)], eds. O.A. Korostelev, S.N. Morozov, series: Akademicheskii Bunin, issue 1. Moscow, Litfakt Publ., 2019, pp. 704-727. (In Russ.).

Ponomarev E.R. Ot "Zhizni Arsen'eva" k "Temnym alleiam": Emigrantskoe tvorchestvo I.A. Bunina $\mathrm{v}$ svete poslednikh tekstologicheskikh izyskanii [From "Arseniev's Life" to "Dark Alleys": Bunin's émigré works in the light of recent textual research]. Russkaia literatura, 2017, no. 4, pp. 228-238. (In Russ.)

\title{
Ivan Bunin's prose works. An approach to the choice of copy texts for a critical edition
}

\author{
(C) 2020, Tatiana Dvinyatina, Sergey Morozov
}

\begin{abstract}
This article discusses the choice of copy texts to serve as the basis of a critical edition of Ivan Bunin's prose works. The issue of choosing copy texts has been most thoroughly dealt with in regard to Bunin's poetry, while the text criticism of his prose works is still at an early stage. The multiple stages Bunin's works went through both before and after their publication require methods of presenting his texts to be elaborated which take into consideration both his own work on them and their impact on literary history and on contemporary readers and critics. The present article embodies a first general approach to this subject and outlines a variety of possible solutions to the problems raised. Four groups of Bunin's prose works are examined - those from his early, pre-revolutionary and émigré periods, and those he left unpublished - and an approach to choosing copy texts for each group is explained. A suitable volume structure in a future critical edition of Bunin's works is described. Problems posed by the correct dating of Bunin's stories are analyzed in relation to their chronological position within a future critical edition and the choice of copy texts for them. The basic principles underlying the choice of copy texts of Bunin's prose for a complete scholarly critical edition of his works are presented in conclusion. The article emphasizes that it is impossible to fulfill the last creative will of the author due to the incompleteness of his work with his legacy (selection of works for future editions, uncoordinated editing).
\end{abstract}

Keywords: Ivan Bunin, archive material, text criticism, choice of copy text, collected works.

Information about the authors: Tatiana Dvinyatina, Doctor of Philology, Senior Research Associate, Institute of Russian Literature (Pushkin House) of the Russian Academy of Sciences, Saint Petersburg, Russia. Senior Research Associate, A.M. Gorky Institute of World Literature of the Russian Academy of Sciences, Moscow, Russia. E-mail: tatiana.dvinyatina@gmail.com

Sergey Morozov, PhD, Senior Researcher, A.M. Gorky Institute of World Literature of the Russian Academy of Sciences, Moscow, Russia. E-mail: morozov. sn@yandex.ru

Citation: Dvinyatina Tatiana, Morozov Sergey. Ivan Bunin's prose works. An approach to the choice of copy texts for a critical edition. Literaturnyi fakt, 2020, no. 2 (16), pp. 68-79. DOI 10.22455/2541-8297-2020-16-68-79 